\title{
Rational Construction of a Responsive Azo-Functionalized Porous Organic Framework for $\mathrm{CO}_{2}$ Sorption
}

\author{
Rongrong Yuan ${ }^{1}$, Hao Sun ${ }^{1}$ and Hongming $\mathrm{He}^{2, *}$ (i) \\ 1 Department of Materials Science and Engineering, Jilin Jianzhu University, Changchun 130118, China; \\ yuanrongrong@jlju.edu.cn (R.Y.); sh2456755@163.com (H.S.) \\ 2 Tianjin Key Laboratory of Structure and Performance for Functional Molecules, College of Chemistry, \\ Tianjin Normal University, Tianjin 300387, China \\ * Correspondence: hxxyhhm@tjnu.edu.cn or hehongminghz@163.com
}

check for updates

Citation: Yuan, R.; Sun, H.; He, H.

Rational Construction of a

Responsive Azo-Functionalized Porous Organic Framework for $\mathrm{CO}_{2}$ Sorption. Molecules 2021, 26, 4993. https://doi.org/10.3390/

molecules26164993

Academic Editor: Carlo Santoro

Received: 28 July 2021

Accepted: 12 August 2021

Published: 18 August 2021

Publisher's Note: MDPI stays neutral with regard to jurisdictional claims in published maps and institutional affiliations.

Copyright: (c) 2021 by the authors. Licensee MDPI, Basel, Switzerland. This article is an open access article distributed under the terms and conditions of the Creative Commons Attribution (CC BY) license (https:/ / creativecommons.org/licenses/by/ $4.0 /)$.

\begin{abstract}
An azo-functionalized porous organic framework (denoted as JJU-1) was synthesized via $\mathrm{FeCl}_{3}$-promoted oxidative coupling polymerization. By virtue of a porous skeleton and a light/heat responsive azo functional group, this task-specific JJU-1 displays a reversible stimuli-responsive adsorption property triggered by UV irradiation and heat treatment. The initial Brunauer-EmmetTeller (BET) surface area of this porous material is $467 \mathrm{~m}^{2} \mathrm{~g}^{-1}$. The $\mathrm{CO}_{2}$ sorption isotherms exhibit a slight decrease after UV irradiation because of the trans to cis conversion of the azo functional skeleton. It is worth mentioning that the responsive $\mathrm{CO}_{2}$ adsorption performance can be recycled for three cycles via alternating external stimuli, confirming the excellently reversible switchability of trans-to-cis isomerization and controllable $\mathrm{CO}_{2}$ adsorption.
\end{abstract}

Keywords: porous organic framework; azo; stimuli-responsive; $\mathrm{CO}_{2}$ sorption

\section{Introduction}

As a common greenhouse gas, the increased concentration of carbon dioxide $\left(\mathrm{CO}_{2}\right)$ has caused global ecological and environmental problems. Effective capture and utilization of $\mathrm{CO}_{2}$ is very important for environmental protection and economic value. To settle this thorny problem, one of the most effective approaches is the carbon capture and storage (CCS) technology [1,2]. Recently, many scientists have developed and exploited various materials for high-efficient adsorption of $\mathrm{CO}_{2}$ [3-6]. In the last few decades, porous organic frameworks (POFs) have been attracting a great deal of attention, because they have many advantages including a high surface area, excellent physicochemical stability, convenient designability, and fascinating structure [7-12]. POFs have been synthesized in large quantities and widely investigated in the $\mathrm{CO}_{2}$ sorption field [13-16]. Up to now, various synthetic reactions have been explored in the preparation of $\mathrm{POFs}$, including the Yamamoto reaction [17], the Sonogashira-Hagihara cross-coupling reaction [18], the Suzuki coupling reaction [19], oxidative coupling polymerization [20], and the Friedel-Crafts alkylation reaction [21]. Nevertheless, most polymerization reactions commonly require rigorous reaction conditions in the preparation of POFs, including high temperatures, expensive noble metal catalysts, and inert gas shielding. Recently, the $\mathrm{FeCl}_{3}$-promoted oxidative coupling polymerization has been considered as a potential approach to construct POFs [22-26]. This method possesses outstanding advantages due to the low-cost catalyst, moderate reaction temperature, and high yield. Among all organic monomers, carbazolebased building blocks are easily to construct three-dimensional (3D) porous structures. Meanwhile, carbazole itself has good thermal stability and acid/alkali resistance. Its unique rigid ring and conjugated electron-rich system are not only beneficial to the formation of porous materials, but also can strengthen the interaction between carbazole and the adsorbed substance. The electron-rich carbazole groups can be coupled chemically under an oxidant such as $\mathrm{FeCl}_{3}$ [27-29]. 
Recently, photoresponsive $\mathrm{CO}_{2}$ adsorbents have been attracting lots of attention, because the $\mathrm{CO}_{2}$ adsorption capacity can be adjusted conveniently by light irradiation. As we know, functional materials that respond to different external stimuli, such as redox potential, temperature, $\mathrm{pH}$ value, and light, have been developed and used extensively in various applications [30-35]. The development of sensitive smart materials has become one of the important research areas, because the controllability, rapid responsiveness, and high precision are beneficial in many vital applications. Light is considered as the most attractive among all stimulation forms, because light is a handy and usually non-invasive signal. Photochromic molecules like azobenzene have been attracting particular attention for photoresponsive functional materials [36]. Upon UV irradiation, azobenzene can isomerize from the nonpolar and planar trans-form to the nonplanar cis-form with a dipole moment, which can significantly affect the sorption and release of guest species [37]. Additionally, the cis azobenzene can go back to its thermodynamically stable trans-form via the irradiation with visible light or thermal relaxation. Recently, the azobenzene photoresponsive porous materials have been designed and explored for regulating $\mathrm{CO}_{2}$ adsorption performance [38-45]. It is still very important to design and prepare such functional materials with $\mathrm{CO}_{2}$ storage/release sensitivity and good $\mathrm{CO}_{2}$ separation performance.

Taking the above into account, a carbazole-based organic building block of 1,3-bis(Ncarbazolyl)benzene (BCB) was selected to react with azobenzene (AB) to construct a novel POF material (denoted as JJU-1) by $\mathrm{FeCl}_{3}$-promoted oxidative coupling polymerization (Scheme 1). The as-synthesized JJU-1 has high thermal stability, moderate surface area, and hierarchical pore structure. Furthermore, the $\mathrm{CO}_{2}$ adsorption isotherms of JJU- 1 under UV irradiation and thermal regeneration can be well-repeated for three cycles. The $\mathrm{CO}_{2}$ uptake corresponds to a $11.5 \%$ decrease after UV irradiation, and almost recovers to the initial value after thermal regeneration, indicating the reversibility of the photoresponsive behavior in this prepared porous material. Therefore, the azo-functionalized POF with controllable $\mathrm{CO}_{2}$ adsorption could bring potential applications in CCS.

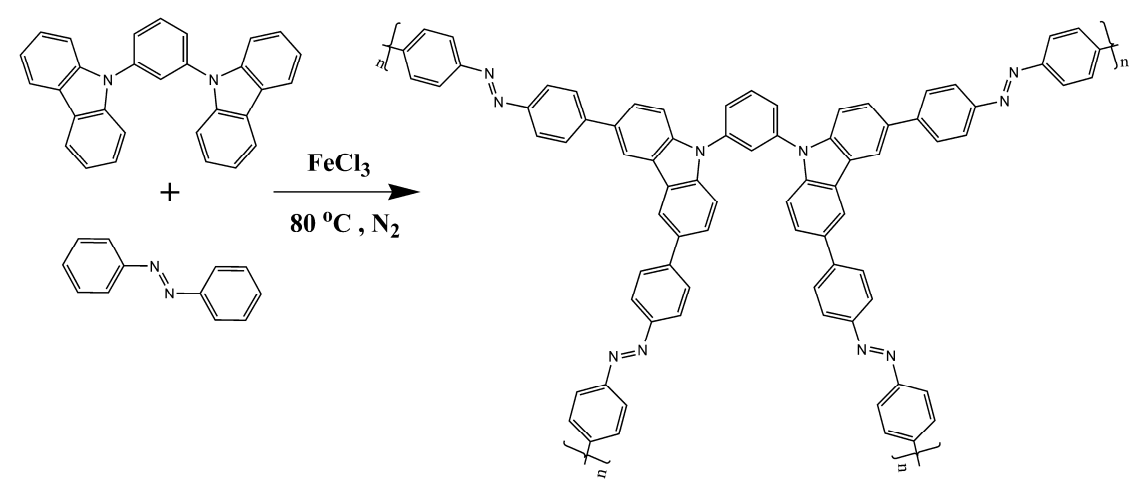

Scheme 1. The synthetic process of JJU-1 via $\mathrm{FeCl}_{3}$-promoted oxidative coupling polymerization.

\section{Results}

\subsection{Structural Description}

Firstly, the trans/cis isomerization of azobenzene as a research model is confirmed by UV-Vis measurements. A typical strong $\pi \rightarrow \pi^{*}$ absorption band at $325 \mathrm{~nm}$ and a weak $\pi \rightarrow \pi^{*}$ absorption band at $435 \mathrm{~nm}$ in dichloromethane can be found in the UV-Vis spectra, which are assigned to the trans and cis isomerization of the azo functional group. After exposure to UV light, the intensity of the $325 \mathrm{~nm}$ band decreases along with the slightly increasing intensity of the $435 \mathrm{~nm}$ band because of the trans-to-cis isomerization of azobenzene (Figure S1). Furthermore, the prepared sample and the UV/heat irradiated samples are fully studied by many technologies. The skeleton structure of JJU-1 is initially investigated by Fourier transform infrared (FT-IR) spectroscopy (Figure 1a). Through comparison of the FT-IR spectra of initial monomers and final products, the characteristic absorption peaks are summed up as follows: (a) an obvious peak at $\sim 3000 \mathrm{~cm}^{-1}$ is mainly 
ascribed to the $\mathrm{C}-\mathrm{H}$ stretching vibration of the hydrogen atom in phenyl ring; (b) the peaks $\left(680 \sim 560 \mathrm{~cm}^{-1}\right)$ belong to the $\mathrm{C}-\mathrm{H}$ deformation vibration of four adjacent hydrogen atoms in the 1,2-disubstituted phenyl ring of carbazole group, which are significantly weakened due to the reduction of adjacent ring hydrogen atoms from four to three; (c) some peaks in the range of $800 \sim 690 \mathrm{~cm}^{-1}$ are the $\mathrm{C}-\mathrm{H}$ deformation vibration of ring hydrogen atoms of the 1,2-disubstituted phenyl ring of the carbazole group; (d) the characteristic stretching band of $-\mathrm{N}=\mathrm{N}-$ at $1445 \mathrm{~cm}^{-1}$ presents in JJU-1 [46]. Furthermore, the ${ }^{13} \mathrm{C}$ solid-state NMR was measured to determine the skeleton structure of JJU-1. As seen in Figure 1b, three prominent peaks are present in the range of $100 \sim 150 \mathrm{ppm}$, belonging to aromatic carbon atoms of the phenyl ring. The strongest signal at $123 \mathrm{ppm}$ is principally assigned to the un-substituted phenyl carbon atom. Meanwhile, both relatively weaker signals at 106 and $137 \mathrm{ppm}$ could be caused by the substituted phenyl carbon atom [47]. This evidence indicate that JJU-1 possesses the objective skeleton. On the other hand, powder X-ray diffraction (PXRD) was used to study the crystallinity of as-synthesized materials. No obvious diffraction peak is found in Figure 1c, suggesting the amorphous nature of JJU-1. As illustrated in Figure 1d, the thermogravimetric analysis (TGA) curve shows that this prepared sample has high thermal stability in air.
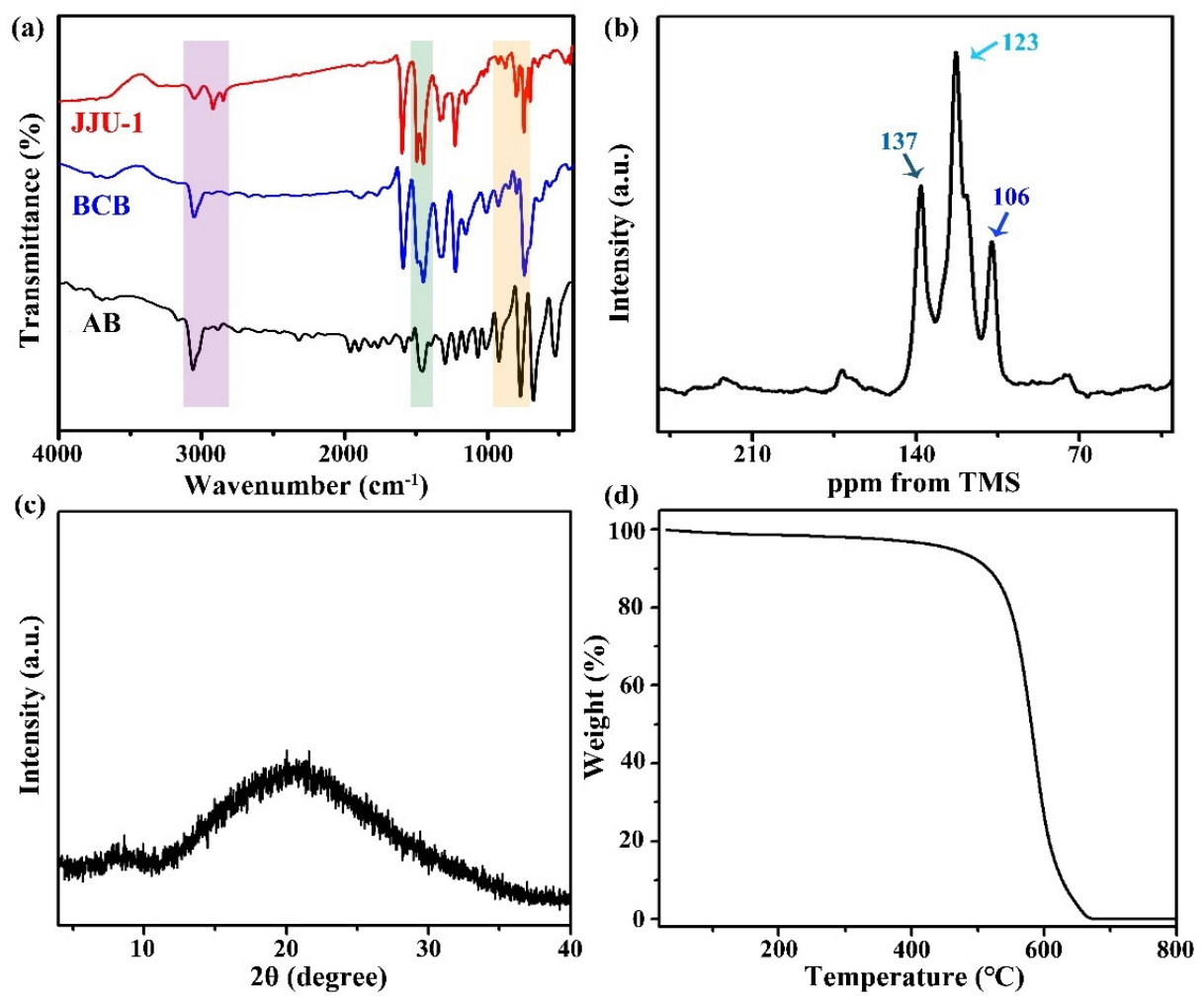

Figure 1. (a) FT-IR spectra of AB (black), BCB (blue) and JJU-1 (red); (b) the ${ }^{13} \mathrm{C}$ solid-state NMR spectrum; (c) PXRD and (d) TGA curve of JJU-1.

Furthermore, scanning electron microscopy (SEM) and transmission electron microscopy (TEM) technologies have been widely used to study the morphology and microstructure. Herein, SEM and TEM images were recorded for inspecting the morphology and structure of as-synthesized JJU-1. As seen in (Figure 2a), the SEM image shows that the prepared solid samples are cross-linked irregular nanoparticles, which is consistent with the PXRD pattern. In addition, the TEM still exhibits that JJU-1 has an out-of-order and worm-like porous structure (Figure 2b). According to these results, the as-synthesized JJU-1 is successfully synthesized as amorphous powder materials. 


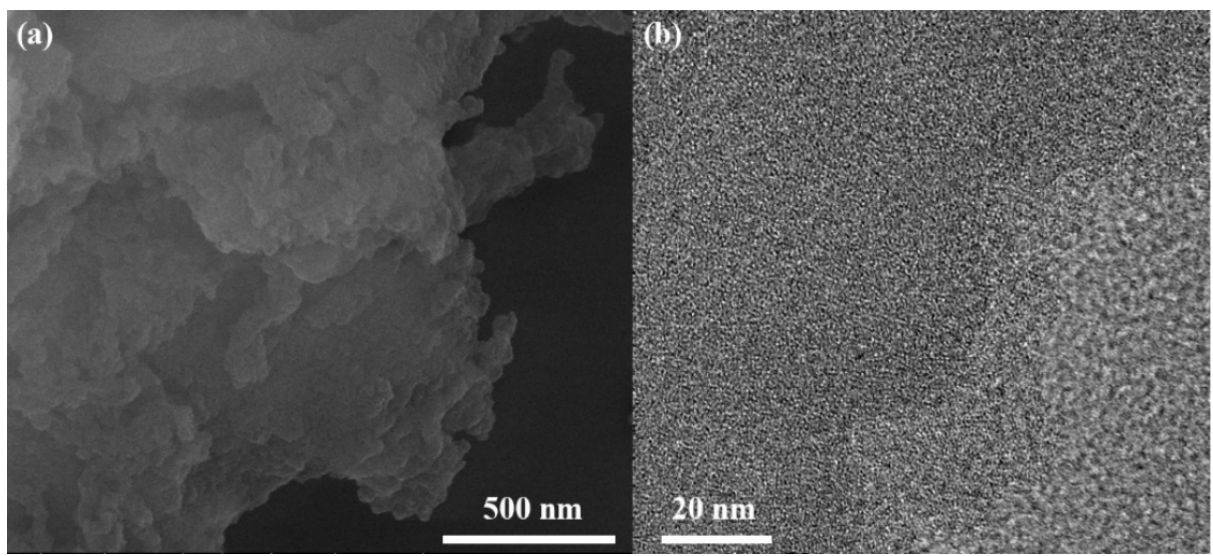

Figure 2. (a) SEM and (b) TEM images of the as-synthesized JJU-1.

\subsection{Gas Sorption Properties}

$\mathrm{N}_{2}$ sorption isotherms of activated samples after heating at $150{ }^{\circ} \mathrm{C}$ for $10 \mathrm{~h}$ under vacuum were measured at $77 \mathrm{~K}$ to investigate the porous structure of JJU-1. As shown in (Figure 3a), the adsorption isotherms are the combination phenomena of type-I and type-IV curves [48], which is widely found in some reported POF materials [49-51]. The $\mathrm{N}_{2}$ adsorption amount can rapidly reach up to $115.9 \mathrm{~cm}^{3} \mathrm{~g}^{-1}$ at $0.1 \mathrm{~atm}$, and the maximum $\mathrm{N}_{2}$ uptake is as high as $200.6 \mathrm{~cm}^{3} \mathrm{~g}^{-1}$ at $1 \mathrm{~atm}$. The $\mathrm{N}_{2}$ sorption performance mainly happens in the micropores, as the sharp adsorption amounts at the low pressure region. Besides, the pore expansion and larger pores cause the distinct hysteresis between the adsorption and desorption plots. Furthermore, the increasing sorption uptake with the boosting pressure proves the existence of mesoporous structure. The surface area of activated JJU-1 is calculated by Langmuir and Brunauer-Emmet-Teller (BET) models. Meanwhile, the pore size distribution of JJU-1 is calculated by the non-local density functional theory (NLDFT). All results are summarized and listed in (Table 1). JJU-1 displays different $\mathrm{N}_{2}$ sorption behaviors at $77 \mathrm{~K}$ after UV light irradiation for $5 \mathrm{~h}$, with a slightly increasing $\mathrm{N}_{2}$ sorption amount (Figure 3a). The BET surface area plots are shown in Figure S2 and Table S1. Although the specific surface area is similar with the initial sample, it is worth mentioning that the micropore size distribution of JJU-1 decreases slightly after UV light irradiation (Figure 3b). In addition, the pore volume of JJU-1 also slightly changes after UV light irradiation. These results prove that the introduction of azobenzene into the porous skeleton is an efficient approach for regulating the pore property of POFs.
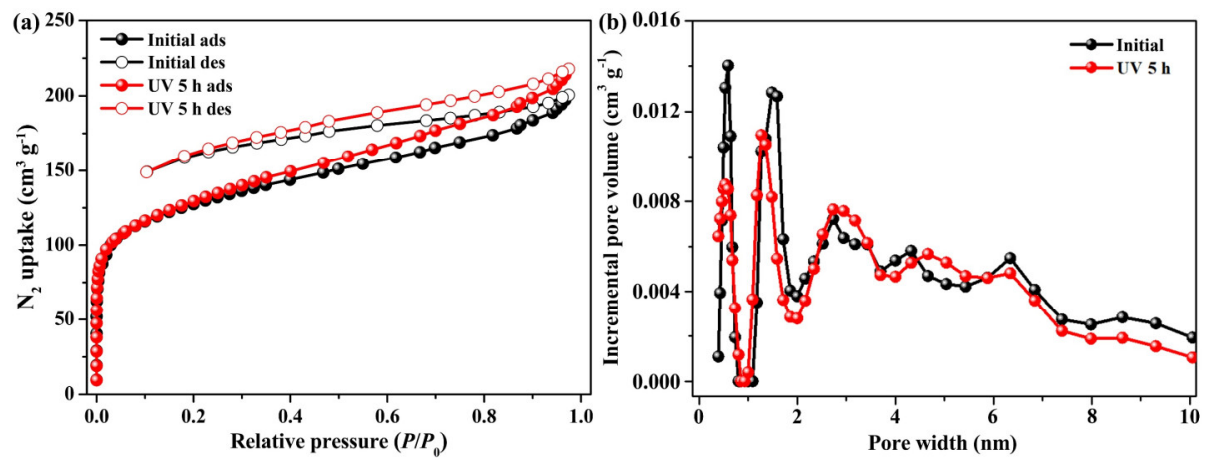

Figure 3. (a) $\mathrm{N}_{2}$ adsorption and desorption isotherms and (b) pore size distributions of initial JJU-1 (black) and after UV irradiation for $5 \mathrm{~h}$ (red). 
Table 1. Summary of porosity, pore volume and $\mathrm{CO}_{2}$ adsorption properties for JJU-1.

\begin{tabular}{|c|c|c|c|c|c|c|c|}
\hline \multirow[t]{2}{*}{ Samples } & \multirow[t]{2}{*}{$\begin{array}{l}\mathrm{SA}_{\mathrm{BET}}{ }^{\mathrm{a}} \\
{\left[\mathrm{m}^{2} \mathrm{~g}^{-1}\right]}\end{array}$} & \multirow[t]{2}{*}{$\begin{array}{c}\mathrm{SA}_{\text {Langmuir }} \mathrm{b} \\
{\left[\mathrm{m}^{2} \mathrm{~g}^{-1}\right]}\end{array}$} & \multirow[t]{2}{*}{$\begin{array}{c}V_{\text {Total }}{ }^{c} \\
{\left[\mathrm{~cm}^{3} \mathrm{~g}^{-1}\right]}\end{array}$} & \multirow[t]{2}{*}{$\begin{array}{l}V_{\text {Micro }^{d}} \\
{\left[\mathrm{~cm}^{3} \mathrm{~g}^{-1}\right]}\end{array}$} & \multicolumn{2}{|c|}{$\begin{array}{c}\mathrm{CO}_{2} \text { Uptake } \\
{\left[\mathrm{cm}^{3} \mathrm{~g}^{-1}\right]}\end{array}$} & \multirow[t]{2}{*}{$\begin{array}{c}\mathrm{Q}_{\mathrm{st}} \mathrm{CO}_{2} \\
\left(\mathrm{~kJ} \mathrm{\textrm {mol } ^ { - 1 }}\right)\end{array}$} \\
\hline & & & & & $273 \mathrm{~K}$ & $298 \mathrm{~K}$ & \\
\hline Initial & 467 & 530 & 0.31 & 0.15 & 45.3 & 26.3 & 27.1 \\
\hline UV $5 \mathrm{~h}$ & 469 & 532 & 0.34 & 0.17 & 40.1 & 23.2 & 33.1 \\
\hline
\end{tabular}

a Surface area $\left(\mathrm{m}^{2} \mathrm{~g}^{-1}\right)$ calculated from the $\mathrm{N}_{2}$ adsorption based on the BET model; ${ }^{\mathrm{b}}$ Surface area $\left(\mathrm{m}^{2} \mathrm{~g}^{-1}\right)$ calculated from the $\mathrm{N}_{2}$ adsorption isotherms based on the Langmuir model; ${ }^{\mathrm{c}}$ The total pore volume $\left(\mathrm{cm}^{3} \mathrm{~g}^{-1}\right)$ calculated at $P / P_{0}=0.97$; ${ }^{\mathrm{d}}$ The micropore volume $\left(\mathrm{cm}^{3} \mathrm{~g}^{-1}\right)$ calculated by the t-plot method.

According to previous reports, the trans/cis isomerization of azobenzene is able to generate apparent geometrical and dipole changes [52-55]. $\mathrm{CO}_{2}$ sorption tests were carried out to obtain the uptake capacity, which can be used to investigate the dynamic photoswitching for controllable $\mathrm{CO}_{2}$ adsorption of JJU-1. As seen in (Figure 4a), the initial JJU-1 can obviously adsorb a large amount of $\mathrm{CO}_{2}$ at 273 and $298 \mathrm{~K}$ at $1 \mathrm{~atm}$, with maximum uptakes of 45.3 and $26.3 \mathrm{~cm}^{3} \mathrm{~g}^{-1}$. Nevertheless, JJU-1 after UV irradiation for 5 h shows significantly different $\mathrm{CO}_{2}$ adsorption behaviors (Figure $4 \mathrm{~b}$ ). Furthermore, the $\mathrm{CO}_{2}$ adsorption enthalpy $\left(\mathrm{Q}_{\mathrm{st}}\right)$ can be calculated based on $\mathrm{CO}_{2}$ sorption isotherms at $273 \mathrm{~K}$ and $298 \mathrm{~K}$ (Figure 4c and Figure S3). The $\mathrm{Q}_{\mathrm{st}}$ value of the initial sample toward $\mathrm{CO}_{2}$ is calculated as $27.1 \mathrm{~kJ} \mathrm{~mol}^{-1}$. The $\mathrm{Q}_{\mathrm{st}}$ value of JJU-1 after UV irradiation for $5 \mathrm{~h}$ is obviously different from that of initial samples; meanwhile, the corresponding $\mathrm{Q}_{\mathrm{st}}$ value increases to $33.1 \mathrm{~kJ} \mathrm{~mol}^{-1}$. The configuration change of azobenzene from trans to cis results in an increased affinity for $\mathrm{CO}_{2}$; however, the reduction of micropore volume is the major reason for the decreasing $\mathrm{CO}_{2}$ adsorption after $\mathrm{UV}$ irradiation. More importantly, the $\mathrm{CO}_{2}$ sorption isotherms of the material after UV irradiation and thermal regeneration were repeatedly measured for three cycles. Figure $4 \mathrm{~d}$ and Figure $\mathrm{S} 4$ show the detailed $\mathrm{CO}_{2}$ adsorption isotherms at $273 \mathrm{~K}$ under $1 \mathrm{~atm}$. No obvious variation of the $\mathrm{CO}_{2}$ adsorption behavior was observed during the trans/cis isomerization of the azo-functional skeleton after recycling three times via alternating external stimuli (Table 2). Comparison with the previous reported materials, this prepared JJU-1 exhibits outstanding $\mathrm{CO}_{2}$ sorption performance under controlled external stimuli (Table S2). Additionally, the gas sorption behaviors may be mainly caused by the reversible trans/cis transformation of the azo functional group under UV irradiation and thermal regeneration (Figure S5). Three UV irradiation/thermal relaxation cycles confirm the reversible behavior during the $\mathrm{CO}_{2}$ storage/release process. As a result, the introduction of the azo group in POFs is beneficial to the synthesis of photoresponsive POFs toward $\mathrm{CO}_{2}$.

Table 2. Summary of $\mathrm{CO}_{2}$ adsorption properties of JJU-1.

\begin{tabular}{cc}
\hline JJU-1 & $\mathbf{C O}_{\mathbf{2}}$ Uptake (273 $\mathbf{~}, \mathbf{1}$ bar), $\left[\mathbf{c m}^{\mathbf{3}} \mathbf{g}^{-\mathbf{1}}\right]$ \\
\hline Initial & 45.3 \\
1st UV & 40.1 \\
1st Heat & 45.0 \\
2nd UV & 39.3 \\
2nd Heat & 43.1 \\
3rd UV & 38.7 \\
3rd Heat & 43.1 \\
\hline
\end{tabular}



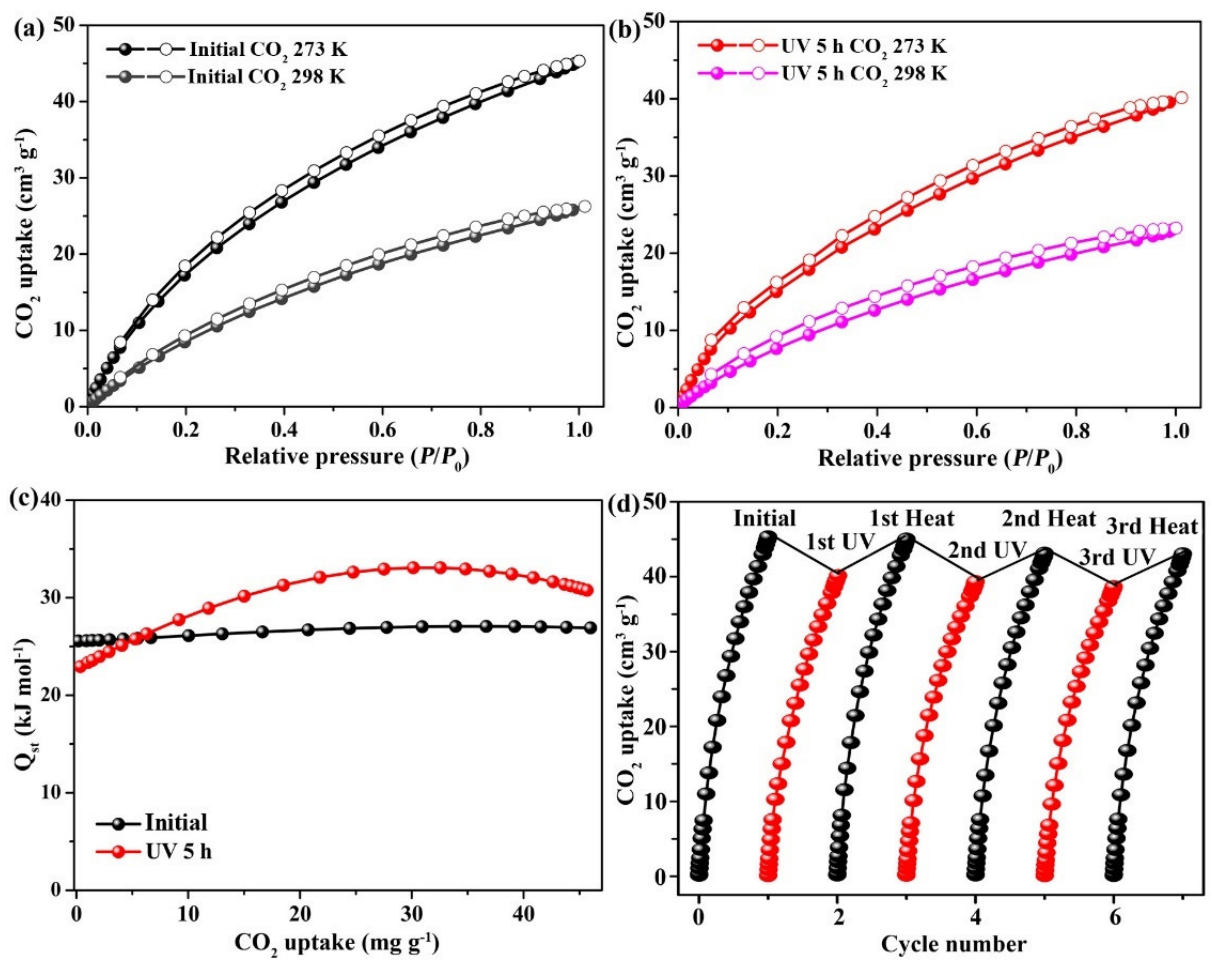

Figure 4. $\mathrm{CO}_{2}$ adsorption isotherms of (a) initial JJU-1 and (b) JJU-1 after UV irradiation for $5 \mathrm{~h}$; (c) the corresponding $\mathrm{Q}_{\text {st }}$ plots; (d) the reversibility of JJU-1 after UV and heat treatment for three cycles.

\section{Materials and Methods}

\subsection{Materials and General Methods}

All available chemicals were purchased commercially and used as received without further purification. Notably, $\mathrm{CHCl}_{3}$ was dried over $\mathrm{CaH}_{2}$ before using in the synthetic process. UV-Vis spectra were recorded on Mapada V-1200 (Shanghai Meipuda instrument Co., LTD, Shanghai, China). The UV exposure experiments for trans to cis isomerization were performed by a ZF-1A UV analyzer (JIAPENG, Shanghai, China). The FT-IR spectra were recorded on an IFS 66V/S Fourier transform infrared spectrometer (Bruker Corporation, Rheinstetten, Germany). The ${ }^{13} \mathrm{C} C \mathrm{CP}-\mathrm{MAS}$ spectrum was recorded in a Bruker AV-400-WB (Bruker Corporation, Billerica, MA, USA). PXRD was performed on a Rigaku D/MAX 2550 diffractometer (Rigaku, Tokyo, Japan) by using $\mathrm{Cu}-\mathrm{K} \alpha$ radiation at $40 \mathrm{kV}$ and $200 \mathrm{~mA}$ over a $2 \theta$ range of $4-40^{\circ}$. SEM images were measured on a MIRA-3 LMU scanning electron microscope (Tescan, Brno, The Czech Republic). TEM images were collected on a Tecnai G ${ }^{2}$ F20 S-TWIN (FEI, Hillsboro, WA, USA). TGA was implemented on a PerkinElmer STA6000 thermal analyzer (PERKINELMER, Waltham MA, USA) in air at a heating rate of $10{ }^{\circ} \mathrm{C} \mathrm{min}{ }^{-1}$. Gas sorption measurements were measured on a Micromeritics ASAP $2020 \mathrm{M}$ surface at $77 \mathrm{~K}$ (Micromeritics Instrument Corporation, Norcross, GA, USA). For the cis to trans isomerization, the degassing port on a Micromeritics ASAP 2020 gas sorption analyser was used by setting the program to $150^{\circ} \mathrm{C}$ for $10 \mathrm{~h}$.

\subsection{Synthesis of JJU-1}

A mixture of 1,3-bis( $\mathrm{N}$-carbazolyl)benzene ( $204 \mathrm{mg}, 0.5 \mathrm{mmol})$, azobenzene ( $456 \mathrm{mg}$, $2.5 \mathrm{mmol})$, and $\mathrm{FeCl}_{3}(487 \mathrm{mg}, 3 \mathrm{mmol})$ was added in a round-bottomed flask. After pumping into a vacuum, the reaction system was trice inflated with inert $\mathrm{N}_{2}$. Then, dried $\mathrm{CHCl}_{3}(20 \mathrm{~mL})$ was added through a syringe. The mixture was heated to $80^{\circ} \mathrm{C}$ under $\mathrm{N}_{2}$ atmosphere for $24 \mathrm{~h}$. After cooling to room temperature, the crude product was obtained by filtration and washed with water, chloroform, methanol and acetone to remove unreacted monomers or catalyst residues. Further purification of as-synthesized JJU-1 was carried out 
by the Soxhlet extraction with methanol for $48 \mathrm{~h}$. The final product was dried in a vacuum for $6 \mathrm{~h}$ at $60^{\circ} \mathrm{C}$ to give the target samples.

\section{Conclusions}

In this work, an azo-containing POF has been successfully synthesized via $\mathrm{FeCl}_{3-}$ promoted oxidative coupling polymerization. The structure and porosity of the prepared material are well characterized and discussed. The trans/cis isomerization of azo group in the porous skeleton is achieved by UV irradiation and thermal regeneration. The $\mathrm{CO}_{2}$ uptake corresponds to a $11.5 \%$ decrease after UV irradiation, and almost recovers to the initial value after thermal regeneration. Furthermore, the $\mathrm{CO}_{2}$ adsorption isotherms of the POF using UV irradiation and thermal regeneration are repeatedly measured for three cycles. This work proves that responsive azo-functionalized POFs with controllable adsorption of $\mathrm{CO}_{2}$ have great potential applications in CCS, and are worthy of further study.

Supplementary Materials: The following are available online, Figure S1: Changes in the adsorption spectra of azobenzene in $\mathrm{CH}_{2} \mathrm{Cl}_{2}$ over the time during the irradiation with $365 \mathrm{~nm}$ light; Figure S2: BET surface area plots; Figure S3: The plots of pressures in function of gas uptakes and the parameters (virial-type expression) for the calculation of heats of adsorption of $\mathrm{CO}_{2}$ for (a) initial JJU-1 and (b) JJU-1-1st UV; Figure S4: The reversible $\mathrm{CO}_{2}$ adsorption isotherms at $273 \mathrm{~K}$ by UV irradiation and thermal treatment of JJU-1; Figure S5: The schematic diagram of the structure changes during the reversible trans/cis transformation of azo functional group under UV irradiation and thermal regeneration; Table S1: The BET surface area report of JJU-1; Table S2: BET surface area reports and $\mathrm{CO}_{2}$ uptakes of some similar POFs.

Author Contributions: Writing — original draft preparation and funding acquisition, R.Y.; investigation and data curation, H.S.; writing-review and editing, H.H. All authors have read and agreed to the published version of the manuscript.

Funding: This research was funded by the financial support of National Natural Science Foundation of China (21805109).

Institutional Review Board Statement: Not applicable.

Informed Consent Statement: Not applicable.

Data Availability Statement: The data presented in this study are available in the Supplementary Materials.

Conflicts of Interest: The authors declare no conflict of interest.

Sample Availability: Samples of the compounds are Not available from the authors.

\section{References}

1. Yu, J.; Xie, L.H.; Li, J.R.; Ma, Y.; Seminario, J.M.; Balbuena, P.B. $\mathrm{CO}_{2}$ Capture and Separations Using MOFs: Computational and Experimental Studies. Chem. Rev. 2017, 117, 9674-9754. [CrossRef] [PubMed]

2. Gupta, V.; Mandal, S.K. A Highly Stable Triazole-Functionalized Metal-Organic Framework Integrated with Exposed Metal Sites for Selective $\mathrm{CO}_{2}$ Capture and Conversion. Chem. Eur. J. 2020, 26, 2658-2665. [CrossRef] [PubMed]

3. He, H.; Sun, Q.; Gao, W.; Perman, J.A.; Sun, F.; Zhu, G.; Aguila, B.; Forrest, K.; Space, B.; Ma, S. A Stable Metal-Organic Framework Featuring a Local Buffer Environment for Carbon Dioxide Fixation. Angew. Chem. Int. Edit. 2018, 57, 4657-4662. [CrossRef] [PubMed]

4. Pelech, I.; Sibera, D.; Staciwa, P.; Narkiewicz, U.; Cormia, R. Pressureless and Low-Pressure Synthesis of Microporous Carbon Spheres Applied to $\mathrm{CO}_{2}$ Adsorption. Molecules 2020, 25, 5328. [CrossRef] [PubMed]

5. He, H.; Perman, J.A.; Zhu, G.; Ma, S. Metal-Organic Frameworks for $\mathrm{CO}_{2}$ Chemical Transformations. Small 2016, 12, 6309-6324. [CrossRef]

6. Demakov, P.A.; Volynkin, S.S.; Samsonenko, D.G.; Fedin, V.P.; Dybtsev, D.N. A Selenophene-Incorporated Metal-Organic Framework for Enhanced $\mathrm{CO}_{2}$ Uptake and Adsorption Selectivity. Molecules 2020, 25, 4396. [CrossRef]

7. Tian, Y.Y.; Zhu, G.S. Porous Aromatic Frameworks (PAFs). Chem. Rev. 2020, 120, 8934-8986. [CrossRef] [PubMed]

8. Han, Z.-Y.; Li, H.-K.; Zhu, Q.-Q.; Yuan, R.; He, H. An Intriguing Electrochemical Impedance Aptasensor Based on a Porous Organic Framework Supported Silver Nanoparticles for Ultrasensitively Detecting Theophylline. Chin. Chem. Lett. 2021. [CrossRef] 
9. Tan, L.X.; Tan, B. Hypercrosslinked Porous Polymer Materials: Design, Synthesis, and Applications. Chem. Soc. Rev. 2017, 46, 3322-3356. [CrossRef]

10. Han, Z.-Y.; Zhu, Q.-Q.; Zhang, H.-W.; Yuan, R.; He, H. A Porous Organic Framework Composite Embedded with Au Nanoparticles: An Ultrasensitive Electrochemical Aptasensor toward Detection of Oxytetracycline. J. Mater. Chem. C 2020, 8, 14075-14082. [CrossRef]

11. Chen, P.; Sun, J.S.; Zhang, L.; Ma, W.Y.; Sun, F.X.; Zhu, G.S. Porous Aromatic Framework (PAF-1) as Hyperstable Platform for Enantioselective Organocatalysis. Sci. China Mater. 2019, 62, 194-202. [CrossRef]

12. Cardoso, V.F.; Correia, D.M.; Ribeiro, C.; Fernandes, M.M.; Lanceros-Mendez, S. Fluorinated Polymers as Smart Materials for Advanced Biomedical Applications. Polymers 2018, 10, 161. [CrossRef]

13. Krishnaraj, C.; Jena, H.S.; Lecoeuvre, F.; Leus, K.; van der Voort, P. Rigid Nanoporous Urea-Based Covalent Triazine Frameworks for $\mathrm{C}_{2} / \mathrm{C}_{1}$ and $\mathrm{CO}_{2} / \mathrm{CH}_{4}$ Gas Separation. Molecules 2021, 26, 3670. [CrossRef] [PubMed]

14. Krishnan, S.; Suneesh, C.V. Post-Synthetic Modification of Fluorenone Based Hypercrosslinked Porous Copolymers for Carbon Dioxide Capture. J. Solid State Chem. 2021, 299, 122152. [CrossRef]

15. Maya, E.M.; Valverde-Gonzalez, A.; Iglesias, M. Conversion of $\mathrm{CO}_{2}$ into Chloropropene Carbonate Catalyzed by Iron (II) Phthalocyanine Hypercrosslinked Porous Organic Polymer. Molecules 2020, 25, 4598. [CrossRef]

16. Xu, G.; Zhu, Y.; Xie, W.; Zhang, S.; Yao, C.; Xu, Y. Porous Cationic Covalent Triazine-Based Frameworks as Platforms for Efficient $\mathrm{CO}_{2}$ and Iodine Capture. Chem. Asian J. 2019, 14, 3259-3263. [CrossRef]

17. Yu, H.; Xu, S.; Liu, Y.; Chen, H.; Li, H. A Porous Organic Poly(triphenylimidazole) Decorated with Palladium Nanoparticles for the Cyanation of Aryl Iodides. Chem. Asian J. 2018, 13, 2708-2713. [CrossRef] [PubMed]

18. Hu, C.; Gao, Y.C.; Zhang, C.; Liu, M.; Geng, T.M. The Effects of the Crosslinking Position and Degree of Conjugation in Perylene Tetraanhydride Bisimide Microporous Polymers on Fluorescence Sensing Performance. RSC Adv. 2020, 10, 5108-5115. [CrossRef]

19. Wang, D.Y.; Wang, W.J.; Wang, R.; Xi, S.C.; Dong, B. A Fluorescent Covalent Triazine Framework Consisting of Donor-Acceptor Structure for Selective and Sensitive sensing of $\mathrm{Fe}^{3+}$. Eur. Polym. J. 2021, 147, 110297. [CrossRef]

20. Feng, L.J.; Chen, Q.; Zhu, J.H.; Liu, D.P.; Zhao, Y.C.; Han, B.H. Adsorption Performance and Catalytic Activity of Porous Conjugated Polyporphyrins via Carbazole-Based Oxidative Coupling Polymerization. Polym. Chem. 2014, 5, 3081-3088. [CrossRef]

21. Wu, Y.; Li, L.; Yang, W.; Feng, S.; Liu, H. Hybrid Nanoporous Polystyrene Derived from Cubic Octavinylsilsesquioxane and Commercial Polystyrene via the Friedel-Crafts Reaction. RSC Adv. 2015, 5, 12987-12993. [CrossRef]

22. Yuan, R.; Yan, Z.; Shaga, A.; He, H. Design and Fabrication of an Electrochemical Sensing Platform Based on a Porous Organic Polymer for Ultrasensitive Ampicillin Detection. Sensor. Actuat. B Chem. 2021, 327, 128949. [CrossRef]

23. Krusenbaum, A.; Graetz, S.; Bimmermann, S.; Hutsch, S.; Borchardt, L. The Mechanochemical Scholl Reaction as a Versatile Synthesis Tool for the Solvent-Free Generation of Microporous Polymers. RSC Adv. 2020, 10, 25509-25516. [CrossRef]

24. Yuan, R.; He, H. Construction of an Electrochemical Aptasensor Based on a Carbazole-Bearing Porous Organic Polymer for Rapid and Ultrasensitive Detection of Penicillin. Appl. Surf. Sci. 2021, 563, 150307. [CrossRef]

25. Qian, L.; Hong, H.; Han, M.; Xu, C.; Wang, S.; Guo, Z.; Yan, D. A Ketone-Functionalized Carbazolic Porous Organic Framework for Sensitive Fluorometric Determination of $p$-Nitroaniline. Microchim. Acta 2019, 186, 457. [CrossRef]

26. Hao, S.; Liu, Y.; Shang, C.; Liang, Z.; Yu, J. CO 2 Adsorption and Catalytic Application of Imidazole Ionic Liquid Functionalized Porous Organic Polymers. Polym. Chem. 2017, 8, 1833-1839. [CrossRef]

27. Malacrida, C.; Lu, Y.; Dirnberger, K.; Gámez-Valenzuela, S.; Delgado, M.C.R.; Ludwigs, S. Towards Highly Conducting Bicarbazole Redox Polymer Films with Plateau-Like Conductivities. J. Mater. Chem. C 2020, 8, 15393-15405. [CrossRef]

28. Yang, X.-L.; Hu, D.-Y.; Chen, Q.; Li, L.; Li, P.-X.; Ren, S.-B.; Bertuzzo, M.; Chen, K.; Han, D.-M.; Zhou, X.-H.; et al. A Pyrene-Cored Conjugated Microporous Polycarbazole for Sensitive and Selective Detection of Hazardous Explosives. Inorg. Chem. Commun. 2019, 107, 107453. [CrossRef]

29. Qiao, S.; Du, Z.; Yang, R. Design and Synthesis of Novel Carbazole-Spacer-Carbazole Type Conjugated Microporous Networks for Gas Storage and Separation. J Mater. Chem. A 2014, 2, 1877-1885. [CrossRef]

30. Coskun, A.; Banaszak, M.; Astumian, R.D.; Stoddart, J.F.; Grzybowski, B.A. Great Expectations: Can Artificial Molecular Machines Deliver on Their Promise? Chem. Soc. Rev. 2012, 41, 19-30. [CrossRef]

31. Hazra, A.; Bonakala, S.; Adalikwu, S.A.; Balasubramanian, S.; Maji, T.K. Fluorocarbon-Functionalized Superhydrophobic MetalOrganic Framework: Enhanced $\mathrm{CO}_{2}$ Uptake via Photoinduced Postsynthetic Modification. Inorg. Chem. 2021, 60, $3823-3833$. [CrossRef] [PubMed]

32. Cobo, I.; Li, M.; Sumerlin, B.S.; Perrier, S. Smart Hybrid Materials by Conjugation of Responsive Polymers to Biomacromolecules. Nat. Mater. 2015, 14, 143-159. [CrossRef]

33. Aznar, E.; Oroval, M.; Pascual, L.; Murguia, J.R.; Martinez-Manez, R.; Sancenon, F. Gated Materials for on-Command Release of Guest Molecules. Chem. Rev. 2016, 116, 561-718. [CrossRef]

34. Zakrzewski, J.J.; Heczko, M.; Jankowski, R.; Chorazy, S. Reversible Humidity-Driven Transformation of a Bimetallic $\{$ EuCo\} Molecular Material: Structural, Sorption, and Photoluminescence Studies. Molecules 2021, 26, 1102. [CrossRef]

35. Vassalini, I.; Alessandri, I. Switchable Stimuli-Responsive Heterogeneous Catalysis. Catalysts 2018, 8, 569. [CrossRef] 
36. Geng, J.S.; Liu, K.; Liang, Y.Y.; Yu, J.P.; Hu, K.Q.; Yuan, L.H.; Feng, W.; Chai, Z.F.; Mei, L.; Shi, W.Q. An Azobenzene-Modified Photoresponsive Thorium-Organic Framework: Monitoring and Quantitative Analysis of Reversible trans-cis Photoisomerization. Inorg. Chem. 2021, 60, 8519-8529. [CrossRef] [PubMed]

37. Bandara, H.M.D.; Burdette, S.C. Photoisomerization in Different Classes of Azobenzene. Chem. Soc. Rev. 2012, 41, 1809-1825. [CrossRef]

38. Bera, R.; Ansari, M.; Alam, A.; Das, N. Triptycene, Phenolic-OH, and Azo-Functionalized Porous Organic Polymers: Efficient and Selective $\mathrm{CO}_{2}$ Capture. ACS Appl. Polym. Mater. 2019, 1, 959-968. [CrossRef]

39. Cheng, L.; Jiang, Y.; Qi, S.-C.; Liu, W.; Shan, S.-F.; Tan, P.; Liu, X.-Q.; Sun, L.-B. Controllable Adsorption of $\mathrm{CO}_{2}$ on $\mathrm{Smart}$ Adsorbents: An Interplay between Amines and Photoresponsive Molecules. Chem. Mater. 2018, 30, 3429-3437. [CrossRef]

40. Huang, R.; Hill, M.R.; Babarao, R.; Medhekar, N.V. CO $\mathrm{CO}_{2}$ Adsorption in Azobenzene Functionalized Stimuli Responsive MetalOrganic Frameworks. J. Phys. Chem. C 2016, 120, 16658-16667. [CrossRef]

41. Yuan, R.; Ren, H.; He, H.; Jiang, L.; Zhu, G. Targeted Synthesis of Porous Aromatic Frameworks with Stimuli-Responsive Adsorption Properties. Sci. China Mater. 2015, 58, 38-43. [CrossRef]

42. Maity, D.K.; Dey, A.; Ghosh, S.; Halder, A.; Ray, P.P.; Ghoshal, D. Set of Multifunctional Azo Functionalized Semiconducting $\mathrm{Cd}(\mathrm{II})-\mathrm{MOF}$ Showing Photoswitching Property and Selective $\mathrm{CO}_{2}$ Adsorption. Inorg. Chem. 2018, 57, 251-263. [CrossRef] [PubMed]

43. Yang, C.T.; Kshirsagar, A.R.; Eddin, A.C.; Lin, L.-C.; Poloni, R. Tuning Gas Adsorption by Metal Node Blocking in Photoresponsive Metal-Organic Frameworks. Chem. Eur. J. 2018, 24, 15167-15172. [CrossRef]

44. Jiang, Y.; Tan, P.; Qi, S.C.; Liu, X.Q.; Yan, J.H.; Fan, F.; Sun, L.B. Metal-Organic Frameworks with Target-Specific Active Sites Switched by Photoresponsive Motifs: Efficient Adsorbents for Tailorable $\mathrm{CO}_{2}$ Capture. Angew. Chem. Int. Edit. 2019, 58, 6600-6604. [CrossRef]

45. Yuan, R.; Sun, H.; Yan, Z.; He, H. Rational Design and Synthesis of a Task-Specific Porous Organic Framework Featured Azobenzene as a Photoresponsive Low-Energy $\mathrm{CO}_{2}$ Adsorbent. J. Solid State Chem. 2021, 297, 122049. [CrossRef]

46. Li, S.; Prasetya, N.; Ladewig, B.P. Investigation of Azo-COP-2 as a Photoresponsive Low-Energy CO 2 Adsorbent and Porous Filler in Mixed Matrix Membranes for $\mathrm{CO}_{2} / \mathrm{N}_{2}$ Separation. Ind. Eng. Chem. Res. 2019, 58, 9959-9969. [CrossRef]

47. Yuan, R.; Yan, Z.; Shaga, A.; He, H. Solvent-Free Mechanochemical Synthesis of a Carbazole-Based Porous Organic Polymer with High $\mathrm{CO}_{2}$ Capture and Separation. J. Solid State Chem. 2020, 287, 121327. [CrossRef]

48. Thommes, M.; Kaneko, K.; Neimark, A.V.; Olivier, J.P.; Rodriguez-Reinoso, F.; Rouquerol, J.; Sing, K.S.W. Physisorption of Gases, with Special Reference to the Evaluation of Surface Area and Pore Size Distribution (IUPAC Technical Report). Pure Appl. Chem. 2015, 87, 1051-1069. [CrossRef]

49. Xing, G.; Yan, T.; Das, S.; Ye, L.; Ye, K. Charged Porous Organic Frameworks Bearing Heteroatoms with Enhanced Isosteric Enthalpies of Gas Adsorption. RSC Adv. 2018, 8, 20434-20439. [CrossRef]

50. Wang, M.; Wang, S.; Song, X.; Liang, Z.; Su, X. Photo-Responsive Oxidase Mimic of Conjugated Microporous Polymer for Constructing a pH-Sensitive Fluorescent Sensor for Bio-Enzyme Sensing. Sensor. Actuat. B Chem. 2020, 316, 128157. [CrossRef]

51. Wang, S.; Wang, M.; Liu, Y.; Meng, X.; Ye, Y.; Song, X.; Liang, Z. Novel D- $\pi$-A Conjugated Microporous Polymer as Visible Light-Driven Oxidase Mimic for Efficient Colorimetric Detection of Glutathione. Sensor. Actuat. B Chem. 2021, $326,128808$. [CrossRef]

52. Li, S.; Zhao, W.; Li, H.; Fang, Q. A Photoresponsive Azobenzene-functionalized Covalent Organic Framework. Chem. J. Chin. Univ. 2020, 41, 1384-1390.

53. Bujak, K.; Nocon, K.; Jankowski, A.; Wolinska-Grabczyk, A.; Schab-Balcerzak, E.; Janeczek, H.; Konieczkowska, J. Azopolymers with Imide Structures as Light-Switchable Membranes in Controlled Gas Separation. Eur. Polym. J. 2019, 118, 186-194. [CrossRef]

54. Kanj, A.B.; Mueller, K.; Heinke, L. Stimuli-Responsive Metal-Organic Frameworks with Photoswitchable Azobenzene Side Groups. Macromol. Rapid Commun. 2018, 39, 1700239. [CrossRef]

55. Mukhopadhyay, R.D.; Praveen, V.K.; Ajayaghosh, A. Photoresponsive Metal-Organic Materials: Exploiting the Azobenzene Switch. Mater. Horiz. 2014, 1, 572-576. [CrossRef] 